\title{
Planned Treatment Duration
}

National Cancer Institute

\section{Source}

National Cancer Institute. Planned Treatment Duration. NCI Thesaurus. Code C139276.

The period of time during which the treatment is intended to be given. 